\title{
Application of Platelet-rich Plasma (PRP) with Different Scaffolds in Tissue Engineering
}

\author{
Reihaneh Seyedebrahimi (iD ${ }^{1}$, Marzieh Sadeghian ${ }^{2}$, Noushin Amirpour ${ }^{3}$, Maliheh Jahromi ${ }^{3}$ and \\ Batool Hashemi-Beni (iD ${ }^{3, *}$ \\ ${ }^{1}$ Department of Anatomical Sciences, Faculty of Medicine, Qom University of Medical Sciences, Qom, Iran \\ ${ }^{2}$ Alzahra Hospital, Isfahan University of Medical Sciences, Isfahan, Iran \\ ${ }^{3}$ Department of Anatomical Sciences, Faculty of Medicine, Isfahan University of Medical Sciences, Isfahan, Iran \\ "Corresponding author: Department of Anatomical Sciences, Faculty of Medicine, Isfahan University of Medical Sciences, Isfahan, Iran. Email: hashemibeni@med.mui.ac.ir
}

Received 2021 October 23; Revised 2021 December 11; Accepted 2022 January 01.

\begin{abstract}
Background: Today, stem cells are the best candidates for cell therapy and tissue engineering. Adipose-derived Stem Cells (ADSCs) are an essential source of cells in replacement therapies of many diseases.

Objectives: This study compared the proliferation of ADSCs in alginate and fibrin scaffolds.

Methods: Adipose-derived stem cells were isolated from adipose tissue and cultured in alginate or fibrin scaffolds with a medium containing PRP $10 \%$ or FBS 10\%. Then, the cell viability percentage was assessed by MTT assay and trypan blue staining. Also, the percentages of living, apoptotic, and necrotic cells were assessed by flow cytometry assay on the fourth and eighth days.

Results: The cell viability rate was significantly higher in the fibrin scaffold group with PRP than in other groups on the fourth and eighth days $(\mathrm{P}<0.05)$. Moreover, the rate of necrotic cells was significantly lower in the fibrin scaffold group than in the other groups $(\mathrm{P}<0.05)$. Besides, the percentage of living cells was significantly higher in the fibrin scaffold group with PRP than in the other groups on the fourth and eighth days $(\mathrm{P}<0.05)$. Also, the percentage of early apoptotic cells was significantly lower in fibrin with PRP than in other groups on the fourth day. There was no significant difference in the rate of late apoptotic cells between the groups ( $\mathrm{P}>0.05)$.

Conclusions: These findings indicate the positive effect of PRP on the survival and proliferation of ADSCs compared with FBS. Therefore, PRP can be considered a suitable supplement to replace animal sera like FBS.
\end{abstract}

Keywords: Platelet-rich Plasma, Fibrin, Alginate, Tissue Engineering

\section{Background}

Millions of people suffer from different diseases worldwide (1). In recent years, tissue engineering has cured many diseases (2). Tissue engineering is a branch of science used in the medical and pharmaceutical fields to regenerate tissues and treat different illnesses. There are three main factors in tissue engineering: Cells, scaffolds, and growth factors (3). Adipose-derived Stem Cells (ADSCs) are a type of stem cell with characteristics such as high cell proliferation (4) and differentiation (5) with many advantages compared to other sources of stem cells (6).

Scaffolds play the same role as extracellular matrix (ECM) and can replace, too (7). Polymers are materials extensively used for creating appropriate scaffolds in tissue engineering. Scaffolds can create synthetic and natural polymers. Alginate and fibrin are natural substances with high application potential in tissue engineering (8).
Fibrin is a matrix protein earned from fibrinogen. Fibrin scaffolds have more applications than synthetic scaffolds for cell proliferation and differentiation (9). Fibrin has the sites for cell adhesion and can play a critical role in cell adhesion, proliferation, and migration (10). Alginate is a linear polysaccharide polymer obtained from algae and bacteria (11). The hydrophilic property of alginate makes it suitable for cell survival, proliferation, and scaffold fabrication while it has mechanical stability (12). Thus, this natural polymer is widely used for cartilage and bone regeneration (13).

Platelet-rich plasma (PRP) contains different growth factors such as PDGF, TGF- $\beta$, VEGF, IGF, and EGF, which can play beneficial roles in apoptosis, angiogenesis, immunomodulation, cell proliferation, and differentiation (14). 


\section{Objectives}

In this study, the effects of alginate and fibrin scaffolds on ADSCs proliferation and survival were evaluated in the presence of PRP or FBS. Besides, the percentages of apoptotic and living cells were compared in different groups.

\section{Methods}

\subsection{Materials}

Phosphate-buffered saline (PBS), low-glucose Dulbecco's modified eagles medium (DMEM), collagenase IA, alginate sodium, plasmin from human plasma, dimethyl sulfoxide (DMSO), and fetal bovine serum (FBS) were supplied by Sigma (USA). Trypsin/EDTA and penicillin/streptomycin were obtained from Gibco (UK). Trypan blue and 3-4,5-dimethyl thiazol-2-yl-2,5-diphenyl tetrazolium bromide (MTT) were purchased from Merck (Germany). Annexin V FITC Apoptosis Detection Kits were supplied by Abcam (USA).

\subsection{Stem Cell Isolation of Adipose Tissue}

Human subcutaneous abdominal white adipose tissue was gained from elective lipoaspirate samples of abdominal fat from patients at Alzahra Hospital of Isfahan after obtaining written informed consent. Adipose tissue was washed several times by PBS. The samples were digested by $0.01 \%$ collagenase type I for $30 \mathrm{~min}$ at $37^{\circ} \mathrm{C}$. Then, the same volume of DMEM was used for cell suspension and centrifuged for enzyme neutralization for $10 \mathrm{~min}$ at 1,500 rpm. The cell pellet was suspended in DMEM, supplemented by $10 \%$ FBS and $1 \%$ penicillin, and then incubated at $37^{\circ} \mathrm{C}$ in $5 \% \mathrm{CO}_{2}$. After the cells reached about $80 \%$ confluence, they were trypsinized and cultured again (15). When the cell density reached $80 \%$ confluence in passage 3 , h-ADSCs trypsinized and $5 \times 10^{5}$ cells were seeded in 24-well plates for four groups, including alginate-FBS, alginate-PRP, fibrin-FBS, and fibrin-PRP.

\subsection{Platelet-rich Plasma Preparation}

Human PRP is derived from the peripheral blood. In this study, PRP was obtained from blood bags in the blood bank of Alzahra Hospital, Isfahan. Briefly, $20 \mathrm{~mL}$ peripheral blood was collected into falcon tubes and centrifuged at 3,600 rpm for $10 \mathrm{~min}$. The plasma fraction was collected, added $10 \% \mathrm{CaCl}_{2}$, and incubated for PRP activation. Finally, samples were centrifuged at 1,500 rpm for PRP collection.

\subsection{Preparation of Fibrin Scaffolds}

Fibrinogen and fresh frozen plasma (FFP) solutions were obtained from the blood bank of Alzahra Hospital. Then, FFP was melted at $37^{\circ} \mathrm{C}$ for $10 \mathrm{~min}$. Next, $16 \mathrm{~mL}$ of FFP was mixed with $10 \mathrm{~mL}$ of $10 \%$ calcium glucuronate. The solution was incubated for $90 \mathrm{~min}$ at $37^{\circ} \mathrm{C}$ and subsequently centrifuged at 2,200 rpm for $10 \mathrm{~min}$. The supernatant was collected as thrombin and stored at $-80^{\circ} \mathrm{C}(16)$. Fibrinogen was extracted from cryoprecipitate, and $500 \mathrm{~mL}$ of fibrinogen was mixed with 500 thrombin. After $10 \mathrm{~min}$, fibrinogen was converted to fibrin by thrombin in each well. Finally, $5 \times 10^{5} \mathrm{~h}$-ADSCs were added to fibrin and $1 \mathrm{cc}$ medium containing low-glucose DMEM supplemented with 10\% FBS or $10 \%$ PRP.

\subsection{Encapsulation and Cell Culture Procedure in Alginate Scaf- folds}

Cells were encapsulated in an alginate scaffold based on a previous study with a slight modification (17). We dissolved 1.2 g alginate powder in $100 \mu \mathrm{L}$ of $0.9 \%$ sodium chloride to prepare the alginate solution. The alginate solution was passed through a filter with a pore size of $0.2 \mu \mathrm{m}$ for decontamination. Then, $1 \times 10^{6} \mathrm{~h}$-ADSCs was mixed with 200 $\mu \mathrm{L}$ of sterile alginate solution. Next, $5 \times 10^{5}$ cell suspension/alginate was added into $\mathrm{CaCl}_{2}$ solution in each well using a 22 gauge needle. After $15 \mathrm{~min}$, the cell suspension became gel-like. The $\mathrm{CaCl}_{2}$ solution was discarded, and $2 \mathrm{~mL}$ of $0.9 \% \mathrm{NaCl}$ was added to each well. Finally, $\mathrm{NaCl}$ solution was discarded, and cells were placed in a $1 \mathrm{cc}$ of medium containing low-glucose DMEM supplemented with 10\% FBS or $10 \%$ PRP.

\subsection{MTT Assay}

The MTT assay was performed to assess the effects of fibrin and alginate scaffolds on the survival and proliferation of h-ADSCs for four and seven days. Briefly, the medium in each well was aspirated, and $400 \mu \mathrm{L}$ of DMEM/F12 free FBS and $40 \mu \mathrm{L}$ of MTT solution were added. The cells were incubated at $37^{\circ} \mathrm{C}$ in $5 \% \mathrm{CO}_{2}$ for $4 \mathrm{~h}$. The supernatant was discarded, and $400 \mu \mathrm{L}$ of DMSO solution was added to extract MTT formazan. After $2 \mathrm{~h}$ incubation in the dark, the absorbance of each well was determined by a microplate reader (Hyperion MPR4) at the wavelength of $540 \mathrm{~nm}$ (15).

\subsection{Flow Cytometry Analysis}

To measure the apoptosis of h-ADSCs, we used a FITC Annexin V Apoptosis Detection Kit according to the manufacturer's instructions on days 4 and 8. First, h-ADSCs were trypsinated, and the binding buffer was mixed with the cell suspension. Then, $5 \mu \mathrm{L}$ of annexin V-FITC and $5 \mu \mathrm{L}$ of propidium iodide (PI) were added to the suspension and 
placed for $20 \mathrm{~min}$ at $4^{\circ} \mathrm{C}$ in the dark. Finally, analysis was performed using a flow cytometer (BD, USA). The negative control was cells without annexin V-FITC-PI.

\subsection{Trypan Blue Staining}

The number of viable cells was calculated using the Trypan blue test on days 4 and 8 . In this method, $10 \mu \mathrm{L}$ of $0.4 \%$ trypan blue was added after placing $10 \mu \mathrm{L}$ cell suspension on the slide. Then, cells were counted under an inverted microscope. In this protocol, viable cells have clear cytoplasm while dead cells appear with blue cytoplasm (18).

\subsection{Statistical Analysis}

All the data were presented as mean \pm standard deviation (SD) and analyzed by one-way ANOVA. Statistical significance was considered at $\mathrm{P}<0.05$.

\section{Result}

\subsection{Cell Culture}

The cells were cultured without microorganism contamination. After 24 hours of incubation, the cells were attached to the flask. Besides, h-ADSCs were observed with a spindle-like shape (Figure $1 \mathrm{~A}$ and $\mathrm{B}$ ). After the third passage and preparation of the scaffold (Figure 2A and C), ADSCs were transferred to alginate or fibrin scaffolds, and the cells changed to a circular shape (Figure 2B and D).

\subsection{In vitro Cytocompatibility of Scaffolds}

The MTT assay was performed to assess the effects of fibrin and alginate scaffolds on the survival and proliferation of h-ADSCs. The results showed that PRP in the medium significantly enhanced the proliferation of cells compared to other groups on days 4 and 8 (Figure 3 ) ( $P \leq 0.01$ ). In addition, the fibrin scaffold with PRP showed a significantly higher cell proliferation than other groups $(\mathrm{P} \leq 0.01)$.

\subsection{Trypan Blue Test}

As shown in Figure 4, the fibrin scaffold with PRP significantly promoted cell viability compared to other groups, as the percentages of viable cells were $94.03 \pm 3.43 \%$ and $97.10 \pm 2.06 \%$ on days 4 and 8 , respectively. Also, the percentage of necrotic cells was significantly lower in the fibrin scaffold with PRP than in other groups $(\mathrm{P} \leq 0.001)$ on days 4 and 8 , but there was no significant difference between the other groups, confirming the MTT results.

\subsection{Annexin V-FITC}

We evaluated the ratio of viable, apoptotic, and necrotic cells in different groups on days 4 and 8 (Figure 5). The results showed that $93.97 \pm 1.67 \%$ and $92.33 \pm 2.80 \%$ of the harvested cells were viable in the fibrin group with PRP on days 4 and 8, respectively, which were significantly higher than in other groups $(\mathrm{P} \leq 0.01)$. The percentage of cells in early-stage apoptosis was significantly lower in the fibrin group with PRP than in other groups on day 4, whereas there was no difference between the fibrin group with PRP and the fibrin group with FBS on day 8. Moreover, there was no difference in the final stage of cell apoptosis and necrosis between the groups on days 4 and 8 ( $\mathrm{P} \geq$ 0.05).

\section{Discussion}

Our findings revealed that PRP could replace FBS in the medium and promote cell proliferation. In the MTT assay, we found that PRP strongly stimulated ADSCs proliferation in the scaffolds. The concentration of PRP can affect cell proliferation and survival.

Many studies could stimulate the rapid growth and proliferation of stem cells in the presence of PRP $(6,19)$. Mardani et al. compared the effect of different concentrations of PRP on chondrogenic differentiation of h-ADSCs, proving that a 10\% concentration of PRP had more beneficial effects on h-ADSC differentiation (6). Therefore, this study used this concentration. Another study found that 10\% PRP might be optimal for increasing mesenchymal stem cells (MSCs), and PRP promoted MSCs differentiation along a chondrogenic line (19). Han et al. showed that ideal PRP should contain $50-100 \mathrm{ng} / \mathrm{mL}$ TGF $\beta 1$ to positively affect the proliferation of human periodontal ligament cells (h-PDLC) in vitro and effectively stimulate alkaline phosphatase activity and osteoblastic differentiation (20). Also, Zhang et al. showed that a low concentration of PRP could induce proliferation and migration of BM-MSCs; also, the osteogenic ability was increased in the presence of PRP(21). It was proven that PRP might increase cell proliferation through activating ERK1/2, JNK, and Akt in many signaling pathways (22).

Scaffolds should provide an environment like the extracellular matrix for cell proliferation and differentiation. Furthermore, scaffolds must not lead to an immune response in the host body (19). Fibrin is biocompatible and non-toxic and makes no inflammatory reactions such as necrosis or fibrosis in the body (23). Therefore, it has many applications in tissue engineering (24). A study evaluated the proliferation, survival, and apoptosis of nucleus pulposus cells in fibrin and alginate scaffolds for two weeks 

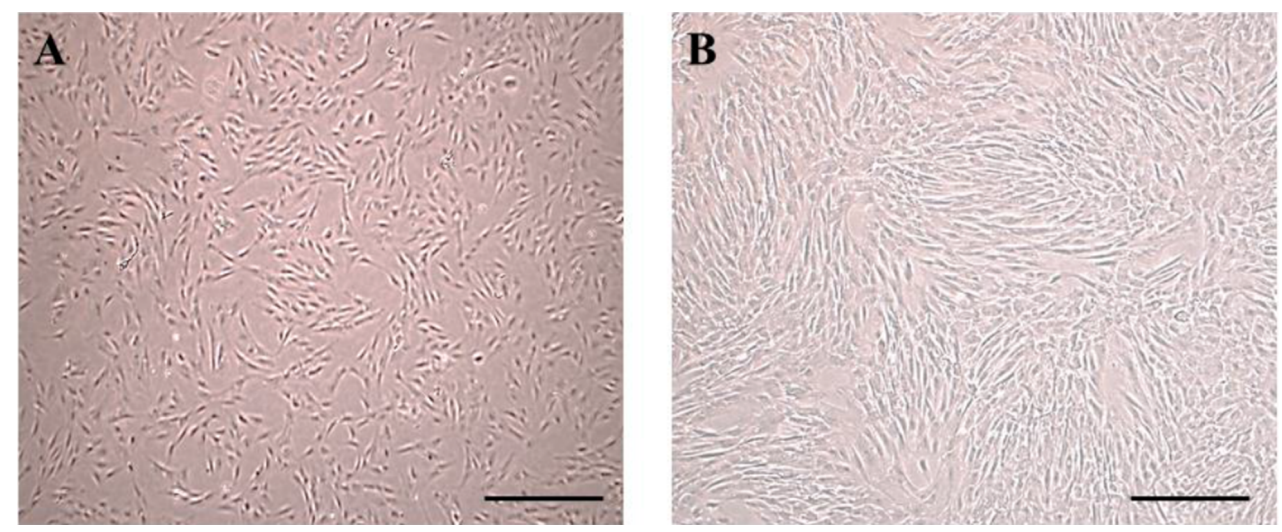

Figure 1. (A) Phase-contrast image of h-ADSCs in passage 3, (B) cells with 80 - 90\% confluence; the morphological characteristics of cells exhibited a fibroblastic-like shape Scale bars are $\mathrm{a}=150 \mu \mathrm{m}$ and $\mathrm{b}=200 \mu \mathrm{m}$
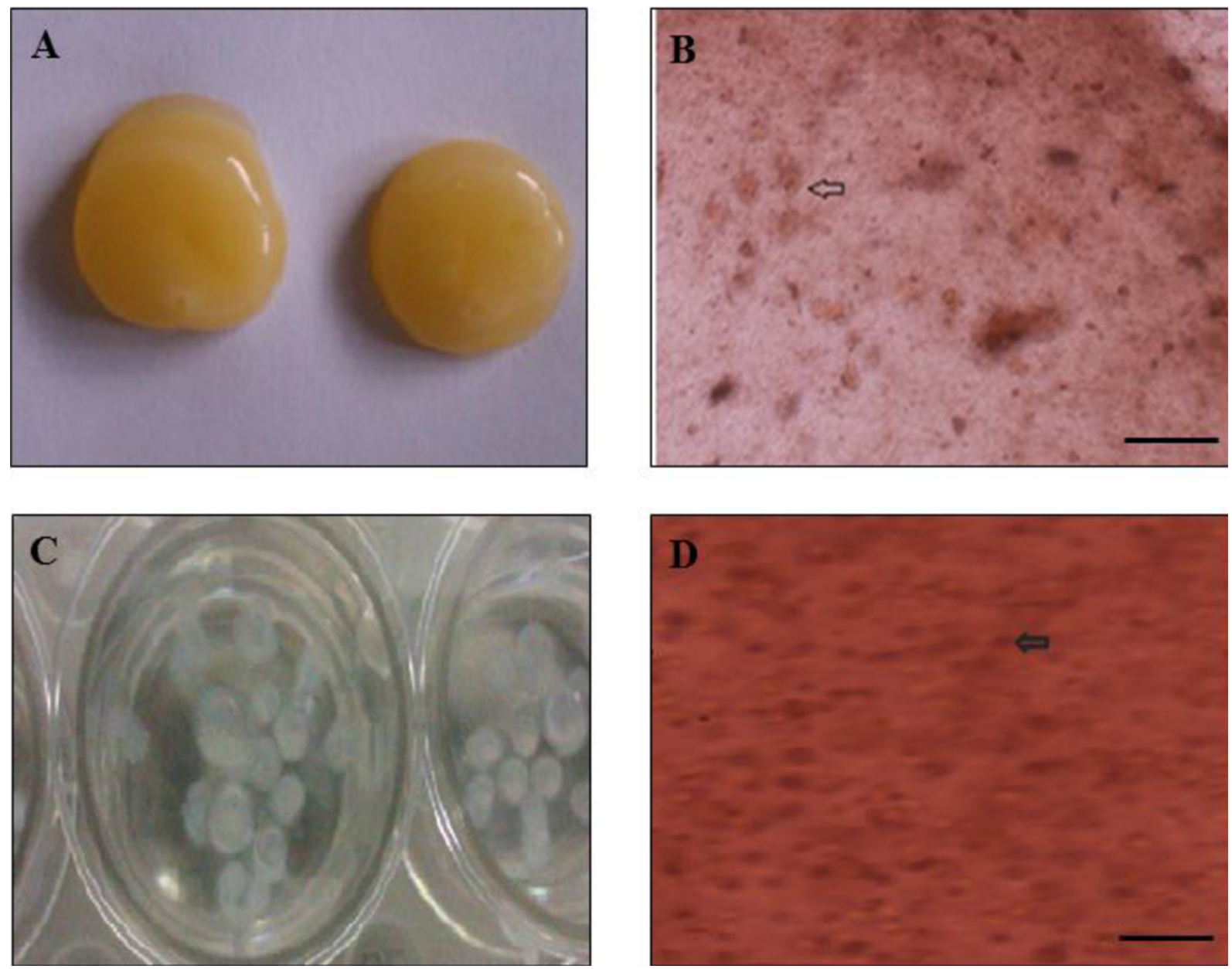

Figure 2. (A) Image of fibrin scaffold, (B) culture of h-ADSCs on the fibrin scaffold with an inverted microscope $(\times 100)$, (C) alginate beads, and (D) image of alginate beads with an inverted microscope $(\times 100)$ 

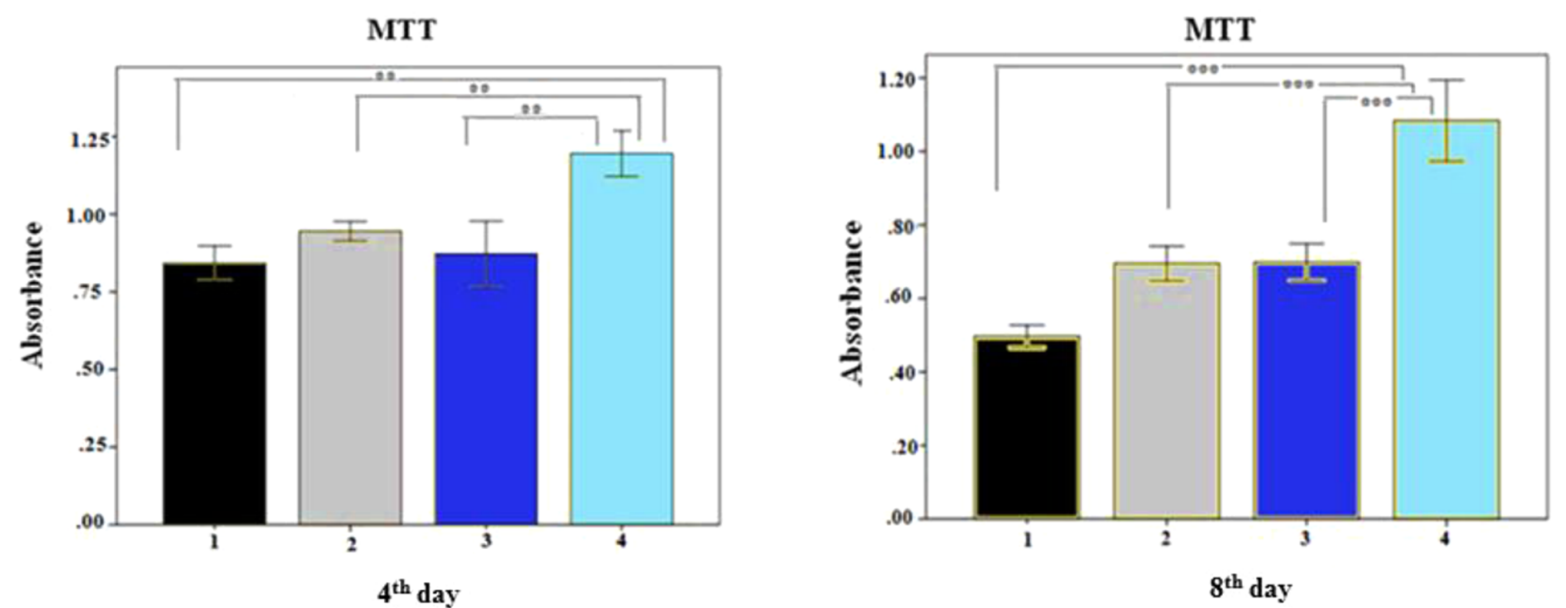

Figure 3. Proliferation of h-ADSCs in different groups: alginate-FBS (1), alginate-PRP (2), fibrin-FBS (3), and fibrin-PRP (4) on days 4 and 8 (mean \pm SEM, ${ }^{* *} \leq 0.01$, $\left.{ }^{* * *} \leq 0.001\right)$
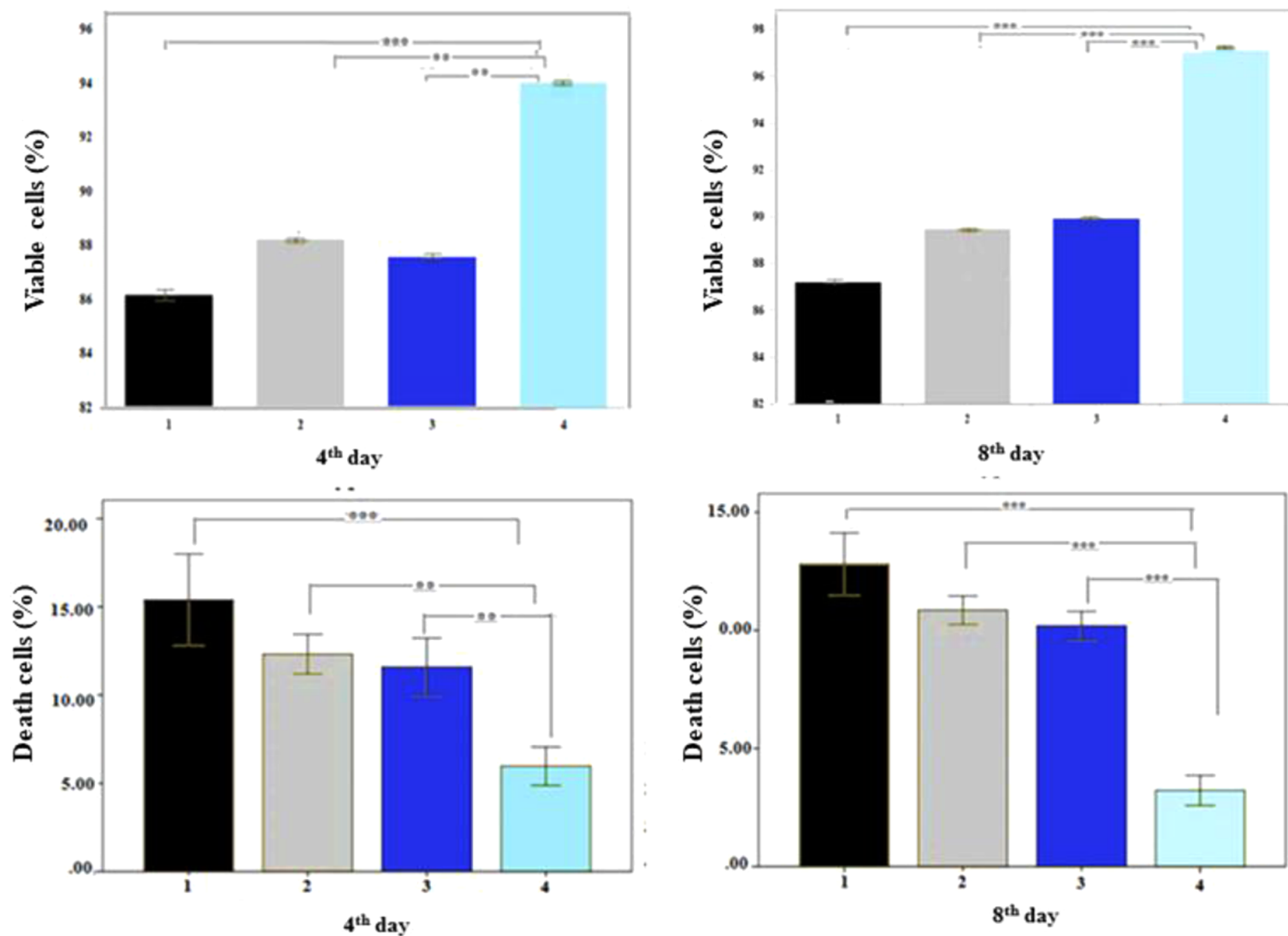

Figure 4. Comparison of trypan blue results among alginate-FBS (1), alginate-PRP (2), fibrin-FBS (3), and fibrin-PRP (4) groups on days 4 and 8 (mean \pm SEM, ${ }^{* *} \leq 0.01,{ }^{* * *} \leq$ 0.001) 
A

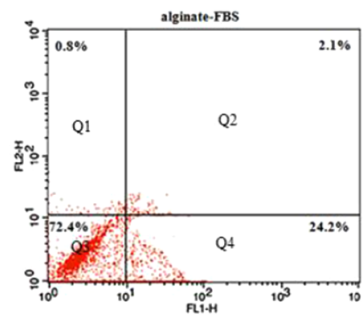

B

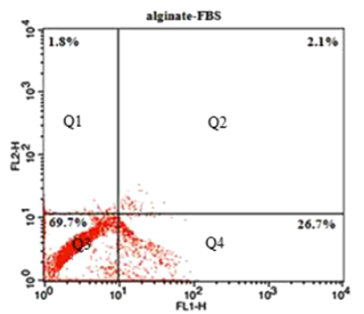

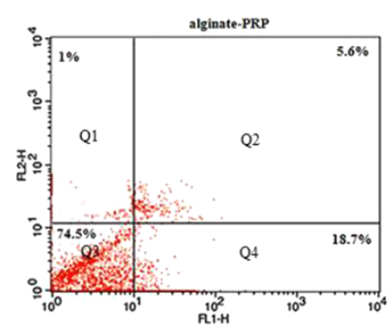
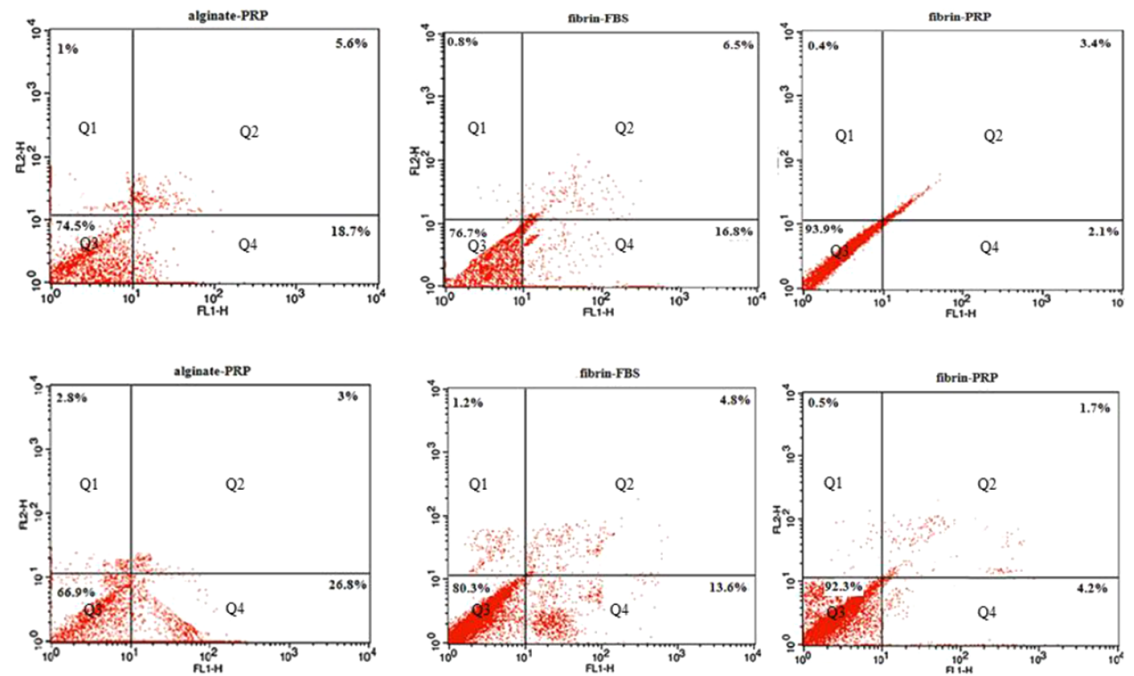

Figure 5. Early and final apoptosis assayed using Annexin V-FITC/PI by flow cytometry in different groups on day 4 (A) and day 8 (B). The cell distribution patterns include necrotic cells (Q1), late apoptotic (Q2), normal viable cells (Q3), and early apoptotic cells (Q4). The highest viable cells were obtained in the Fibrin-PRP group with 93.9\% and $92.3 \%$ on days 4 and 8 , respectively.

(23) and obtained results in line with the present study results. Another study evaluated the mechanical characteristics and cell proliferation in four scaffolds: Human platelet-poor plasma, alginate, fibrin gel, and collagen sponge. The fibrin gel scaffold showed an ideal combination of mechanical characteristics and cell viability compared to other groups (25). Also, the implantation of poly$\varepsilon$-caprolactone/fibrin-alginate scaffold into rat cranial defect model could regenerate the cranial bone defect in rats 4 - 12 weeks post-operation (26). However, we suggest further studies to evaluate the effects of different concentrations of PRP on cell proliferation and cartilage regeneration in vivo using mechanical scaffolds.

\subsection{Conclusions}

In this study, the fibrin scaffold in the presence of PRP provided a suitable environment for cell proliferation. Therefore, we suggest that PRP be used in tissue engineering to replace FBS. This strategy may be effective for cell differentiation and therapies of different diseases, but the clinical application of PRP needs further investigations.

\section{Acknowledgments}

The authors are grateful to Isfahan University of Medical Sciences for financial support.

\section{Footnotes}

Authors' Contribution: Study concept and design: Batool Hashemi-Beni and Reihaneh Seyedebrahimi; Analysis and interpretation of data: Marzieh Sadeghian; Drafting of the manuscript: Noushin Amirpour and Maliheh Jahromi; Critical revision of the manuscript for important intellectual content: Reihaneh Seyedebrahimi and Batool Hashemi-Beni; Statistical analysis: all authors.

Conflict of Interests: The authors declare no conflicts of interest.

Funding/Support: The authors received no financial support for this article's research and/or authorship.

\section{References}

1. Dai R, Wang Z, Samanipour R, Koo KI, Kim K. Adipose-Derived Stem Cells for Tissue Engineering and Regenerative Medicine Applications. Stem Cells Int. 2016;2016:6737345. doi: 10.1155/2016/6737345. [PubMed: 27057174]. [PubMed Central: PMC4761677].

2. Asghari F, Samiei M, Adibkia K, Akbarzadeh A, Davaran S. Biodegradable and biocompatible polymers for tissue engineering application: a review. Artif Cells Nanomed Biotechnol. 2017;45(2):185-92. doi: 10.3109/21691401.2016.1146731. [PubMed: 26923861].

3. Matsiko A, Levingstone TJ, O'Brien FJ. Advanced Strategies for Articular Cartilage Defect Repair. Materials (Basel). 2013;6(2):637-68. doi: 10.3390/ma6020637. [PubMed: 28809332]. [PubMed Central: PMC5452095].

4. Man Y, Wang P, Guo Y, Xiang L, Yang Y, Qu Y, et al. Angiogenic and osteogenic potential of platelet-rich plasma and adipose-derived stem cell laden alginate microspheres. Biomaterials. 2012;33(34):8802-11. doi: 10.1016/j.biomaterials.2012.08.054. [PubMed: 22981779]. 
5. Razavi S, Khosravizadeh Z, Bahramian H, Kazemi M. Time-dependent effect of encapsulating alginate hydrogel on neurogenic potential. Yakhteh. 2015;17(2):304-12.

6. Mardani M, Kabiri A, Esfandiari E, Esmaeili A, Pourazar A, Ansar M, et al. The effect of platelet rich plasma on chondrogenic differentiation of human adipose derived stem cells in transwell culture. Iran J Basic Med Sci. 2013;16(11):1163-9.

7. Razavi S, Razavi MR, Zarkesh Esfahani H, Kazemi M, Mostafavi FS. Comparing brain-derived neurotrophic factor and ciliary neurotrophic factor secretion of induced neurotrophic factor secreting cells from human adipose and bone marrow-derived stem cells. Dev Growth Differ. 2013;55(6):648-55. doi: 10.1111/dgd.12072. [PubMed: 23944834].

8. Tran TT, Hamid ZA, Cheong KY. A review of mechanical properties of scaffold in tissue engineering: aloe vera composites. Journal of Physics: Conference Series. IOP Publishing; 2018.12080 p.

9. Ferreira MS, Jahnen-Dechent W, Labude N, Bovi M, Hieronymus T, Zenke M, et al. Cord blood-hematopoietic stem cell expansion in 3D fibrin scaffolds with stromal support. Biomaterials. 2012;33(29):698797. doi:10.1016/j.biomaterials.2012.06.029. [PubMed: 22800538].

10. Banerjee J, Seetharaman S, Wrice NL, Christy RJ, Natesan S. Delivery of silver sulfadiazine and adipose derived stem cells using fibrin hydrogel improves infected burn wound regeneration. PLoS One.2019;14(6). e0217965. doi:10.1371/journal.pone.0217965. [PubMed: 31194776]. [PubMed Central: PMC6563979].

11. Urtuvia V, Maturana N, Acevedo F, Pena C, Diaz-Barrera A. Bacterial alginate production: an overview of its biosynthesis and potential industrial production. World J Microbiol Biotechnol. 2017;33(11):198. doi: 10.1007/s11274-017-2363-x. [PubMed: 28988302].

12. Purcell EK, Singh A, Kipke DR. Alginate composition effects on a neural stem cell-seeded scaffold. Tissue Eng Part C Methods. 2009;15(4):541-50. doi: 10.1089/ten.tec.2008.0302. [PubMed: 19368511]. [PubMed Central: PMC2819710].

13. Zhang F, Su K, Fang Y, Sandhya S, Wang DA. A mixed co-culture of mesenchymal stem cells and transgenic chondrocytes in alginate hydrogel for cartilage tissue engineering. J Tissue Eng Regen Med. 2015;9(1):77-84. doi: 10.1002/term.1641. [PubMed: 23166064].

14. Everts P, Onishi K, Jayaram P, Lana JF, Mautner K. Platelet-Rich Plasma: New Performance Understandings and Therapeutic Considerations in 2020. Int JMol Sci.2020;21(20). doi: 10.3390/ijms21207794. [PubMed: 33096812]. [PubMed Central: PMC7589810].

15. Shafaei H, Esmaeili A, Mardani M, Razavi S, Hashemibeni B, NasrEsfahani $\mathrm{MH}$, et al. Effects of human placental serum on proliferation and morphology of human adipose tissue-derived stem cells. Bone Marrow Transplant. 2011;46(11):1464-71. doi: 10.1038/bmt.2010.313. [PubMed: 21217787].

16. Tavakoli E, Mehdikhani-Nahrkhalaji M, Hashemi-Beni B, ZargarKharazi A, Kharaziha M. Preparation, Characterization and Mechan- ical Assessment of Poly (Lactide-Co-Glycolide)/ Hyaluronic Acid/ Fibrin/ Bioactive Glass Nano-composite Scaffolds for Cartilage Tissue Engineering Applications. Procedia Manuf Sci. 2015;11:124-30. doi: 10.1016/j.mspro.2015.11.126.

17. Mardani M, Hashemibeni B, Ansar MM, Esfahani SHZ, Kazemi M, Goharian V, et al. Comparison between chondrogenic markers of differentiated chondrocytes from adipose derived stem cells and articular chondrocytes in vitro. Iran J Basic Med Sci. 2013;16(6):763.

18. Strober W. Trypan Blue Exclusion Test of Cell Viability. Curr Protoc Immunol. 2015;111:A3 B 1-3. doi: 10.1002/0471142735.ima03bs111. [PubMed: 26529666]. [PubMed Central: PMC6716531].

19. Bonzani IC, George JH, Stevens MM. Novel materials for bone and cartilage regeneration. Curr Opin Chem Biol. 2006;10(6):568-75. doi: 10.1016/j.cbpa.2006.09.009. [PubMed:17011226].

20. Han J, Meng HX, Tang JM, Li SL, Tang Y, Chen ZB. The effect of different platelet-rich plasma concentrations on proliferation and differentiation of human periodontal ligament cells in vitro. Cell Prolif. 2007;40(2):241-52. doi: 10.1111/j.1365-2184.2007.00430.x. [PubMed: 17472730]. [PubMed Central: PMC6496883].

21. Zhang J, Zhang J, Zhang N, Li T, Zhou X, Jia J, et al. The Effects of Platelet-Rich and Platelet-Poor Plasma on Biological Characteristics of BM-MSCs In Vitro. Anal Cell Pathol (Amst). 2020;2020:8546231. doi: 10.1155/2020/8546231. [PubMed: 32908815]. [PubMed Central: PMC7471809].

22. Lai F, Kakudo N, Morimoto N, Taketani S, Hara T, Ogawa T, et al. Platelet-rich plasma enhances the proliferation of human adipose stem cells through multiple signaling pathways. Stem Cell Res Ther. 2018;9(1):107. doi: 10.1186/s13287-018-0851-z. [PubMed: 29661222]. [PubMed Central: PMC5902971].

23. Yang S, Wu C, Shih TT, Chen P, Lin F. Three-dimensional culture of human nucleus pulposus cells in fibrin clot: comparisons on cellular proliferation and matrix synthesis with cells in alginate. Artificial organs. 2008;32(1):70-3.

24. Christman KL, Vardanian AJ, Fang Q, Sievers RE, Fok HH, Lee RJ. Injectable fibrin scaffold improves cell transplant survival, reduces infarct expansion, and induces neovasculature formation in ischemic myocardium. J Am Coll Cardiol. 2004;44(3):654-60. doi: 10.1016/j.jacc.2004.04.040. [PubMed: 15358036].

25. Girandon L, Kregar-Velikonja N, Bozikov K, Barlic A. In vitro models for adipose tissue engineering with adipose-derived stem cells using different scaffolds of natural origin. Folia Biol (Praha). 2011;57(2):4756.

26. Ren J, Kohli N, Sharma V, Shakouri T, Keskin-Erdogan Z, Saifzadeh S, et al. Poly-epsilon-Caprolactone/Fibrin-Alginate Scaffold: A New ProAngiogenic Composite Biomaterial for the Treatment of Bone Defects. Polymers (Basel). 2021;13(19). doi: 10.3390/polym13193399. [PubMed: 34641215]. [PubMed Central: PMC8512525]. 